\title{
The weapons effect: Fact or artifact?
}

\author{
DELWIN D. CAHOON and ED M. EDMONDS \\ Augusta College, Augusta, Georgia
}

\begin{abstract}
Ninety-six male college students were exposed to handguns or no handguns following positive, neutral, or negative personal evaluation. The weapons were explained either as items of defense ("home defense weapons") or as items of aggression ("guns used in crimes of violent assault"). The dependent measure was hostility or aggression as measured by the Behavior Control Inventory (BCI). The presence or absence of handguns presented as either defensive or offensive weapons was not related to the expression of hostility or aggression. The conclusion is drawn that the weapons effect is a weak variable requiring further research to delineate the conditions of its occurrence.
\end{abstract}

Berkowitz and LePage (1967) reported a study in which firearms appeared to elicit aggressive responding in a laboratory situation. Subsequently, Turner, Layton, and Simons (1975) conducted a study to determine whether these findings could be generalized to a natural setting. Automobile drivers were obstructed by an apparently stalled pickup truck at a traffic light. A rifle in the rear window of the vehicle, coupled with an aggressive bumper sticker ("Vengeance"), increased horn-honking in some blocked drivers if the driver of the truck was not visible. Boyanowsky and Griffiths (1982) found that drivers stopped for traffic violations reacted more aggressively when the arresting officer wore a holstered weapon than when the officer did not. Frodi (1975) found that the weapons effect could be demonstrated with Swedish subjects. D. Page and O'Neal (1977) reported that slides of weapons were also effective in eliciting aggression.

The conclusion that weapons evoke aggression, however, has not been uniformly supported. M. Page and Scheidt (1971) did not find a weapons effect in a replication of the Berkowitz and LePage (1067) study, although they did find an effect related to subject awareness. Subjects who had been exposed to deception in previous social psychology experiments gave fewer shocks when exposed to guns in an aggressive context. Turner and Simons (1974) found that nonapprehensive subjects who knew the purpose of the weapons gave fewer shocks. An attempt by Halderman and Jackson (1979) to replicate the hornhonking study by Turner et al. (1975) in a rural community did not support the weapons effect. Turner et al. concluded that the effect may be negated when the presence of a rifle in the rear window of a pickup truck is commonplace.

Buss, Booker, and Buss (1972) found no evidence that shooting a gun under field conditions was related to aggression in the laboratory. Furthermore, in a careful replication of the Berkowitz and LePage (1967) study, Buss et al. found that the presence of weapons decreased

Reprint requests may be sent to Delwin D. Cahoon, Department of Psychology, Augusta College, Augusta, GA 30910. shocking in a laboratory situation. An attempt by Ellis, Weinir, and Miller (1971) to replicate the Berkowitz and LePage experiment also reported a tendency toward the inhibition of aggressive responding when weapons were present.

A recent study (Cahoon \& Edmonds, 1984) also reported that the presence or absence of handguns was unrelated to aggressive responding following subjects' exposure to negative "first-impression" feedback.

Some of the studies that seem to support the weapons effect have been difficult to interpret. Turner et al. (1975), for example, found that male drivers of older vehicles, and all female drivers, exhibited more horn-honking when no rifle or bumper sticker was present. Although these results are interpreted as reflecting inhibition produced by the rifle in an aggressive context, other interpretations are obviously possible.

Although the evidence for the weapons effect is conflictual, if not contradictory, the concept has had considerable impact upon social policy recommendations. In an article in Psychology Today entitled "How Guns Control Us," Berkowitz (1981) supported stricter gun controls on the basis of his acceptance of the weapons effect. Opposing evidence is given little attention. The American Psychological Association has also taken a position in favor of gun control, presumably on the basis, at least in part, of the literature supporting the weapons effect.

The empirical support for the existence of the weapons effect seems quite ambiguous. The present study represents an effort to contribute additional information related to this socially important issue by comparing the aggressive effects of weapons versus no weapons and the interpretation (defensive or offensive) based upon these weapons, in angered and nonangered subjects.

\section{METHOD}

\section{Subjects}

The subjects were 96 male students at Augusta College recruited from introductory psychology classes and promised an unspecified amount of "extra credit" for participating in an experiment. Because the proj- 
ect was conducted during class time, the students were also excused from class for one 50 -min period.

\section{Procedure}

The subjects were escorted to the Psychology Clinic in groups of 16. Upon entering the clinic, the students passed by a closed door labeled "Law Enforcement Seminar" before they entered a classroom-lounge area. Once in the lounge, the subjects were seated in two rows of eight chairs facing one another. The subjects were then each given a conspicuous number from 1 to 16 to wear so that they might be identified without reference to their names. The subjects were told that they were involved in a study concerning "first impressions" and that they would be rating an individual in the opposite row. In order to provide an apparent basis for judgment, the subjects were asked to state their major and something about their hobbies or interests.

At this point, a specially prepared "First Impressions Inventory" (Cahoon \& Edmonds, 1984) was distributed. A number on each form indicated which person a subject was to rate. The subjects were asked not to indicate in any way whom they were rating. In this manner, firstimpression ratings were obtained on a 5-point scale for physical appearance, personal adjustment, honesty, likability, attractiveness as a work partner, intelligence, and overall first impression.

After the subjects had completed the First Impressions Inventory, one of the two experimenters left the room, taking the completed forms with him. After approximately $3 \mathrm{~min}$, he returned and announced that half of the subjects were to be transferred to another room and that the other half were to remain in the lounge. The assignment was such that none of the subjects who had rated one another were in the same subgroup. On the basis of evidence that the interpretation of an event is related to its tendency to evoke aggression (Berkowitz \& Alioto, 1973), this experimenter, then conversationally indicated to the second experimenter, in the presence of the subjects, either that "the only room available is the room where Public Safety has been holding their law enforcement safety seminar" or that "the only room available is the room where Public Safety has been holding their law enforcement personal assault crimes seminar." The second experimenter then escorted the designated subjects to the room with the sign "Law Enforcement Seminar." Conspicuously displayed on a central table within the room was an assortment of handguns consisting of a Berretta $.25 \mathrm{cal}$., a Berretta $.380 \mathrm{cal}$, a Ruger $.357 \mathrm{cal}$., and a Colt .38 special. Depending upon the weaponsinterpretation condition, the subjects were told either that the handguns represented home defense weapons from a safety seminar being conducted by the College Public Safety Office or that the guns had been used as weapons of aggression in personal assault crimes and that they were demonstration items in a training seminar being presented by the Public Safety Office. The subjects were thus led to believe that the handguns were associated either with self-defense and safety or, conversely, with assault and violence. The subjects seemed to accept these explanations (this acceptance was later confirmed by the exit interview), and no questions were asked. The subjects were then seated in the eight available chairs, each positioned such that the weapons were visible at all times.

Except for the presence of the guns for the subjects in the weapons condition, the procedure was uniform for all subjects. First, the subjects were given a completed First Impressions Inventory and told that this was the form that had been completed for them earlier in the experiment. Actually, the forms had been prepared by the experimenters and fell into one of three categories: a positive condition, in which the form indicated a very positive first impression; a negative condition, in which the rated impression was uniformly negative; and an intermediate, neutral condition.

After examining what was ostensibly their personal rating for a few minutes, the subjects were asked to complete the Behavior Control Inventory (BCI), which had been developed for use in an earlier study (Cahoon \& Edmonds, 1984) and subsequently modified. The BCI was prefaced by the following instructions, also read aloud by the experimenter:

In each of the following situations, please indicate how you would respond toward the person who has just rated you. Your evaluation will later be given to that person. In addition, the person for whom the greatest amount of punishment is recommended will not receive special credit for participating in this experiment. Remember that we are interested in your opinion and therefore there are no "right" or "wrong" answers. Circle each of your answers.

The BCI poses hypothetical situations that involve misbehavior and in which the rater can select from among four responses in dealing with misbehavior. In each item, the person who misbehaves is presumed to be the rater who had just evaluated the subject. An illustrative item reads as follows:

You are a college professor who catches the person who has just rated you cheating on a test. What would you do?

1. Call him into your office and tell him that you will be watching him closely for the rest of the quarter.

2. Give him a "zero" on the test but take no further action.

3. Fail him in the course.

4. Initiate action to have the student dismissed from college for academic dishonesty.

The final item on the BCI, which provides an opportunity to reward or punish the rater, reads as follows:

Indicate below the number of extra points the person who has rated you should be given for participating in this study. Circle your choice.

$$
\begin{array}{llllll}
0 & 2 & 4 & 6 & 8 & 10
\end{array}
$$

The BCI thus provided an opportunity to express hostility, aggression, and psychological harm toward the individual who had evaluated the rater in terms of a favorable, unfavorable, or neutral first impression.

As an instrument, the $\mathrm{BCI}$ possesses considerable face validity; to validate the $\mathrm{BCI}$ further, it was also scored by eight psychologists. All of the pscyhologists were in agreement ( $100 \%$ concordance) with respect to the punitive ratings of the response alternatives for each item. Stability of the BCI in the present study was indicated by a split-half reliability of .92 . The best indication of validity is reflected by the significant main effect in the expected direction on the BCI for the three types of firstimpression feedback (negative, neutral, and positive). The three means were $2.98,2.76$, and 2.02 , respectively, with higher scores indicating increasingly negative responding $[\mathrm{F}(2,84)=20.80$, $\mathrm{p}<.001]$. Maineffect comparisons indicated that persons who received positive firstimpression feedback were significantly more positive toward the rater than were those persons who received neutral or negative feedback $(.001$ level of significance). A final item on the BCI required the subject to recommend extra credit "points" ranging from 0 to 10 to be added to the final examination score of the student who had presumably provided the first-impression feedback. The mean numbers of points recommended by subjects in the negative-, neutral-, and positive-feedback conditions were 5.0,7.38, and 8.87, respectively $[\mathrm{F}(2,84)=10.87, \mathrm{p}<.001]$. Persons receiving positive feedback assigned significantly more extra points than the subjects in either the neutral- or negative-feedback conditions $(\mathrm{p}<.001)$.

After the BCI had been administered, the subjects completed a postexperimental interview form that assessed their awareness of the purpose of the experiment. This form was arranged in a funnel format, with five items ranging in specificity from "What do you think the experiment was about?" to "If you thought the guns had something to do with the experiment, what were your ideas about their purpose?"' Other items appended to the funnel interview asked the subjects to rate their emotional reactions to the first-impression rater along dimensions of hostile, angry, and pleasant feelings. In addition, there were items asking the subjects to rate how the first-impression rating made them feel in terms of confidence and self-esteem, an item asking the subjects how the firstimpression rating influenced their choices on the BCI, and an item asking the subjects to indicate on a rating scale the extent to which the firstimpression feedback might have inhibited their expressions of hostility on the $\mathrm{BCI}$ due to a sense of personal devaluation. The items pertaining to the weapons were given only to those subjects who had been exposed to the handguns. Otherwise, all subjects completed all the items. 
Following the completion of the postexperimental interview form, the subjects were thoroughly debriefed concerning the artificial evaluation provided by the First Impression Inventory, thanked for their participation, and dismissed.

\section{RESULTS AND DISCUSSION}

A $2 \times 2 \times 3$ analysis of variance classified by guns/no guns, aggressive or defensive interpretation of the guns, and the three first-impression feedback conditions (negative, neutral, and positive) indicated that the weapons and interpretation main effects and the interaction effects were not significant as measured by the BCI. As noted earlier, the feedback main effect on the BCI was significant $[\mathrm{F}(2,84)=20.80, \mathrm{p}<.001]$, indicating that differential arousal did result from the first-impression feedback conditions. The number of "extra points" recommended for the first-impression rater followed precisely the same pattern. It is highly probable, therefore, that the $\mathrm{BCI}$ does provide a sensitive measure of relative hostility and aggression. In spite of this fact, however, the presence or absence of weapons, and the interpretation placed upon these weapons, did not significantly affect responding on the $\mathrm{BCI}$.

One possible explanation for a failure to demonstrate the weapons effect might involve subject awareness of the purpose of the experiment. M. Page and Scheidt (1971), for example, found that subjects who had previously been exposed to deception in psychology experiments delivered fewer shocks when weapons were present. This is interpreted as an illustration of what Masling (1966) termed the "screw you" effect, in which aware subjects tend to subvert the perceived aim of the experiment. For this reason, an analysis of the postexperimental awareness questionnaire is of particular interest.

The first item in the questionnaire asked "What do you think the experiment was about?" and was completed by all subjects. No subject in any group specified the actual purpose of the experiment. The majority of subjects accepted the experimental misdirection that the study was an investigation of "first impressions." The next two items asked whether the subjects were suspicious of any aspect of the experiment and, if so, what led to this suspicion. Although a few subjects indicated that they were "suspicious," none was able to identify correctly the aim of the experiment as the basis of this suspicion.

An item presented to subjects only in the gun condition asked, "Do you think the guns had anything to do with the experiment? (Yes/No)." In response to this rather leading question, $20 \%$ of these subjects indicated some degree of suspicion concerning the weapons. When these subjects were asked to indicate their level of suspicion on a 5 -point scale $(1=$ not suspicious; $5=$ very suspicious), the average rating for the weapons group was 2.20 (on the scale $2=$ minimally suspicious). The guncondition subjects were then asked, "If you thought the guns had something to do with the experiment, what were your ideas about their purpose?" None of the subjects was able to specify that the weapons were related to the elicitation of aggression or to performance on the BCI. It is apparent, therefore, that the results of the present study cannot be accounted for in terms of subject awareness of the purpose of the experiment or relevant suspicion with respect to presence of weapons.

The remaining items on the postexperimental questionnaire were designed to assess emotional reactions under the various conditions. A rating of "hostility" toward the first-impression rater (5-point scale) resulted in means of $2.13,1.20$, and 1.0 for negative-, neutral- and positivefeedback conditions, respectively. A significant main effect was therefore found for first-impression feedback $[F(2,84)=12.52, p<.001]$, whereas no such effect was found for the presence or absence of weapons. Individual mean comparisons indicated that persons rated negatively were significantly more hostile than those rated positively $[\mathrm{t}(62)=4.89, \mathrm{p}<.001]$ and that subjects rated negatively were significantly more hostile than those rated in a neutral manner $[\mathrm{t}(62)=4.00, \mathrm{p}<.001]$. These findings indicate further that, although the subjects were effectively angered by negative social feedback, the resulting hostility was not enhanced by the presence or absence of weapons. Similar and parallel results were obtained for ratings of "anger" toward the first-impression rater and, in a reverse direction, for degree of "pleasant feelings" toward the rater.

Another possibility for the failure to demonstrate the weapons effect might lie in subject inhibition related to feelings of personal inadequacy or devaluation induced by the negative first-impression feedback. Turner et al. (1975), in the stalled-pickup-truck experiment described earlier, found that male drivers of older vehicles, and all female drivers, engaged in less horn-honking in an aggressive context. Turner et al. interpreted this finding as possibly reflecting social inhibitions in presumably socially insecure persons when weapons are present. In order to examine this possibility in the present study, the subjects in the negative-first-impression condition were asked to indicate (on a 5-point scale) the extent to which the negative ratings may have resulted in feelings of inferiority or devaluation and therefore in hesitancy in expressing hostility. No differences in inhibition were found between the negative-feedback/gun group and the negativefeedback/no-gun group. Apparently, failure to demonstrate the weapons effect cannot be accounted for in terms of the inhibitory effects of weapons in socially insecure persons.

This study does not support the existence of a weapons effect under the conditions described. This result is consistent with several other reports in the literature, including Buss et al. (1972), Cahoon and Edmonds (1984), Ellis et al. (1971), M. Page and Scheidt (1971), and Turner and Simons (1974).

Other investigators have suggested that the expression of the weapons effect may be attenuated by variables such 
as subject sophistication, demand awareness, evaluation apprehension, social status, and weapon familiarity (e.g., Buss, Booker, \& Buss, 1972; Cahoon \& Edmonds, 1984; Halderman \& Jackson, 1979; Page \& Scheidt, 1971; Turner \& Simons, 1974). It seems improbable, however, that these factors operated to any significant degree in this study, as indicated by random group assignment and a detailed postexperimental interview. Furthermore, the dependent measure of aggression (the $\mathrm{BCI}$ ) appears to be a sensitive measure of hostility, as indicated by differential responding under the three conditions of first-impression feedback. Conversely, the negative-, neutral-, and positive-feedback conditions seem to have led to effective arousal, as indicated by the significant main effect on the BCI. Perhaps the most parsimonious explanation for the failure to demonstrate the weapons effect is either that it does not exist or that it is an exceedingly weak variable obscured by a multitude of unspecified modifying variables.

In summary, the present study is consistent with those reports in the literature that have been unable to demonstrate the weapons effect. Because the evidence for this variable is equivocal at best, further research delineating the conditions of its occurrence is obviously needed.

\section{REFERENCES}

Berkowitz, L. (1981, June). How guns control us. Psychology Today, pp. 11-12.

Berkowitz, L., \& Alioto, J. T. (1973). The meaning of an observed event as a determinant of its aggressive consequences. Journal of Personality and Social Psychology, 28, 206-217.
Berkowitz, L., \& LePAGE, A. (1967). Weapons as aggression-eliciting stimuli. Journal of Personality and Social Psychology, 7, 202-207.

Boyanowsky, E. O., \& GRIFfiths, C. T. (1982). Weapons and eye contact as instigators or inhibitors of aggressive arousal in police-citizen interaction. Journal of Applied Social Psychology, 12, 398-407.

Buss, A., Booker, A., \& Buss, E. (1972). Firing a weapon and aggression. Journal of Personality and Social Psychology, 22, 296-302.

Cahoon, D., \& Edmonds, E. M. (1984). Guns/no guns and the expression of social hostility. Bulletin of the Psychonomic Society, 22, 305-308.

Ellis, D. P., Weinir, P., \& Miller, L. (1971). Does the trigger pull the finger? An experimental test of weapons as aggression-eliciting stimuli. Sociometry, 34, 453-465.

Frodi, A. (1975). The effect of exposure to weapons on aggressive behavior from a cross-cultural perspective. International Journal of Psychology, 10, 283-292.

Halderman, B. T., \& JACKson, T. T. (1979). Naturalistic study of aggression: Aggressive stimuli and honking: A replication. Psychological Reports, 45, 880-882.

MasLING, J. (1966). Role-related behavior of the subject and psychologist and its effect upon psychological data. Nebraska Symposium on Motivation, 14, 67-103.

PAGE, D., \& O'Neal, E. (1977). "Weapons effect" without demand characteristics. Psychological Reports, 41, 29-30.

PAGE, M., \& SCHEIDT, R. (1971). The elusive weapons effect: Demand awareness, evaluation apprehension, and slightly sophisticated subjects. Journal of Personality and Social Psychology, 20, 304-318.

TURner, C. W., LAYTon, J. F., \& Simons, L. S. (1975). Naturalistic studies of aggressive behavior: Aggressive stimuli, victim visibility, and horn-honking. Journal of Personality and Social Psychology, 31, 1098-1107.

TURneR, C. W., \& Simons, L. S. (1974). Effects of subject sophistication and evaluation apprehension on aggressive responding to weapons. Journal of Personality and Social Psychology, 30, 341-348.

(Manuscript received for publication October 3, 1984.) 